\title{
Impact of Low-Dose Intracoronary Alteplase Infusion after Successful Primary Percutaneous Coronary Intervention
}

\section{Ismail Mohamed Ibrahim* and Mahmoud Abdel Aziz}

\author{
Department of Cardiology, Zagazig University, Zagazig, Egypt \\ *Corresponding author: Ismail Mohamed Ibrahim, Department of Cardiology, Zagazig University, \\ Zagazig, Egypt, Tel: +201145262020
}

\begin{abstract}
Background and aim: In ST elevation myocardial infarction (STEMI), intracoronary thrombolysis after primary percutaneous coronary intervention (PPCl) was found to improve microvascular perfusion, yet without improvement in left ventricular (LV) remodeling. Our study aimed to find out possible effect on LV longitudinal function.

Methods and results: 102 anterior STEMI patients eligible for $\mathrm{PPCl}$ were divided into: Alteplase group (53 patients; received intracoronary $0.3 \mathrm{mg} / \mathrm{kg}$ alteplase after $\mathrm{PPCl}$ ) and control group (49 patients; treated with PPCI only). LV longitudinal function was assessed using tissue Doppler imaging (to measure mean $S^{\prime}$ and maximum Q-S' time difference) and speckle tracking (to measure global longitudinal strain (GLS)) 48 hours and 6 months after PPCl. In alteplase group, epicardial ( $p$ value $<0.001$ for corrected TIMI frame count) and myocardial perfusion ( $p$ value for myocardial blush grade 0.03 ) were significantly higher. GLS and LV synchrony were better in alteplase group both at 48 hours ( $p$ value 0.02 and $<0.001$ respectively) and at 6 months ( $p$ value $<0.001$ for each). No difference in bleeding rates was noted between groups.
\end{abstract}

Conclusion: Adjunctive low-dose alteplase infusion after $\mathrm{PPCl}$ improves microvascular perfusion and LV longitudinal function without increasing bleeding risk.

\section{Introduction}

The corner stone in ST elevation myocardial infarction (STEMI) management is timely and successful recanalization of infarct related artery (IRA) using primary percutaneous coronary intervention (PPCI) [1]. However, this may be hampered by the occurrence of tissue-level non-perfusion termed microvascular occlusion (MVO) which adversely affects final infarct size
[2] and LV function [3-7]. In addition to the metabolic derangement of reperfusion injury $[8,9]$, both proximal embolization $[10,11]$ and microvascular in-situ thrombosis [12] play role in microvascular damage.

The use of intra-coronary thrombolysis (e.g. Alteplase) immediately after PPCl was tested and showed improved epicardial and microvascular coronary flow [12-14].

Recently, global longitudinal strain (GLS) has emerged as a readily accessible and reproducible tool for estimation of microvascular damage [15] and final infarct size [16] comparable to the gold standard cardiac magnetic resonance (CMR). To the best of our knowledge, we are the first to study the acute and intermediate term effects of intra-coronary alteplase on GLS.

\section{Patients and Methods}

We included 106 consecutive STEMI patients eligible for PPCl. They were divided into 2 groups: Alteplase group (53 patients who received intracoronary alteplase after successful PPCl) and control group (53 patients who were treated with successful PPCl only). All patients were given the necessary information about the study. Zagazig University, Faculty of Medicine ethics committee approved our study, and written informed consent was obtained from all patients.

\section{Inclusion criteria}

- First anterior wall STEMI suitable for PPCI of the infarct related artery (IRA).

Citation: Ibrahim IM, Aziz MA (2019) Impact of Low-Dose Intracoronary Alteplase Infusion after Successful Primary Percutaneous Coronary Intervention. Int J Clin Cardiol 6:149. doi.org/10.23937/23782951/1410149

Accepted: June 03, 2019; Published: June 05, 2019

Copyright: (c) 2019 Ibrahim IM, et al. This is an open-access article distributed under the terms of the Creative Commons Attribution License, which permits unrestricted use, distribution, and reproduction in any medium, provided the original author and source are credited. 
- TIMI coronary flow grade 0-1 and TIMI thrombus grade $>2$ at initial angiography.

\section{Exclusion criteria}

- Previous myocardial infarction, or previous $\mathrm{PCl}$ or coronary artery by-pass grafting (CABG).

- Patients with atrial fibrillation, complete left bundle branch block or significant valvular lesions.

- TIMI flow grade 3 at initial angiography.

- Angiographically unsuccessful PPCI defined as TIMI flow $0-1$, no-reflow, $>20 \%$ residual stenosis at the culprit lesion and/or mechanical complication (e.g. spasm or dissection).

- Presence of additional lesion causing $>50 \%$ stenosis distal to the culprit lesion or in the non-IRA.

- Patients with contraindications for alteplase.

- Patients who were not adherent or compliant to maximum tolerable medical treatment during follow-up.

- Patients with poor echocrdiographic windows.

\section{Methods}

All patients were subjected to the following:

\section{History taking and clinical examination}

With emphasis on coronary artery disease (CAD) major risk factors (hypertension, diabetes mellitus, smoking, dyslipidemia). Killip classification [17] was used to determine the degree of patient's decompensation.

\section{Resting 12-lead surface electrocardiography (ECG)}

On admission and 90 min after PPCl. Successful ST resolution was defined as $>50 \%$ resolution of ST-segment in the lead(s) with maximum ST elevation at 90 min of reperfusion in relation to the baseline ECG [18].

\section{Laboratory work up including CK-MB and troponin I}

Level on admission and serially every 24 hours to determine the peak level. A $20 \%$ or greater elevation of troponin level from the previous sample is considered reinfarction when associated with chest pain with or without dynamic ECG changes [19].

\section{Primary $\mathrm{PCl}$}

Using Judkins technique through radial approach. Computer-assisted randomization of patients was done. Balloon dilatation and stenting was left to the discretion of the attending operator. Export ${ }^{\circledR}$ catheter was used for manual thrombectomy as well as alteplase infusion for patients in alteplase group. The dose used was $0.3 \mathrm{mg} /$ $\mathrm{kg}$ as previously [13] which was infused just proximal to stent level over 5 minutes. The last angiogram was taken 15 minutes after completing the infusion.

Angiographic definitions: Pre- and post-procedural
TIMI thrombus grade (TTG) and TIMI flow were assessed as previously described [20]. Corrected TIMI frame count (CTFC) was assessed as described by Gibson, et al. [21]. Myocardial blush grade (MBG) was grades as described by van't Hof, et al. [22].

Peri-PCI medications: Before $\mathrm{PCl}$, oral aspirin (300 $\mathrm{mg}$ ) and oral ticagrelor (180 $\mathrm{mg}$ ) were given. During the procedure, intravenous unfractionated heparin was given at a dose of $60 \mathrm{U} / \mathrm{kg}$ followed by additional boluses to reach and maintain an activated clotting time around 250 and $280 \mathrm{~s}$. A bolus of tirofiban $(0.1 \mu \mathrm{g} / \mathrm{kg})$ was given 3 minutes after the start of the procedure, followed by continuous infusion at $0.15 \mu \mathrm{g} / \mathrm{kg} /$ minute for 12 hours. After $\mathrm{PCl}$, aspirin $75-100 \mathrm{mg} / 24 \mathrm{~h}$, ticagrelor $90 \mathrm{mg} / 12$ $\mathrm{h}$, maximum guideline-directed tolerable doses of beta-blockers, statins, and angiotensin-converting enzyme inhibitors/angiotensin II receptor blockers.

Adverse in-hospital bleeding events were defined as any bleeding within $24 \mathrm{~h}$ after $\mathrm{PPCl}$ and were graded according to TIMI criteria [23].

\section{Trans-thoracic echocardiography}

Was done $48 \mathrm{~h}$ and 6 months after PPCI.

Volumes of left ventricle at end-diastole (LVEDV) and end-systole (LVESV) and LV ejection fraction (LVEF) from the apical four-chamber view were calculated in accordance with recommendations of the American Society of Echocardiography.

Tissue Doppler imaging: Was performed to assess peak systolic velocity $\left(S^{\prime}\right)$ in the apical 4-chamber and 2-chamber views at the level of the septal, lateral, inferior, and anterior mitral annulus. Measurements were taken separately and averaged [24]. The degree of LV longitudinal dyssynchrony was measured as the maximum difference between $Q-S^{\prime}$ times from different sites of mitral annulus. Q-S' time represent the period between the $Q$ wave in the simultaneous ECG and peak S' wave [25].

Speckle tacking echocardiography: To measure global longitudinal strain (GLS) from optimal 4-chamber, 2-chamber and 3-chamber views and the average was taken [26].

\section{Statistical analysis}

Data were imported into SPSS version 16.0 software (SPSS Inc., Chicago, IL) to be analyzed. Results were presented as mean \pm SD for continuous variables and as frequency (\%) for categorical variables. Data were tested for normality using the Kolmogorov-Smirnov test. Means were compared using the Student $t$ test or Mann-Whitney test. Categorical data were compared using the $\chi^{2}$ Test. $P$ value was set at $<0.05$ for significant results and $<0.001$ for highly significant results.

\section{Results}

Of the 53 patients in control group, 4 patients were 
Table 1: Comparison between groups regarding demographic and procedural data.

\begin{tabular}{|c|c|c|c|c|}
\hline \multirow{2}{*}{\multicolumn{2}{|c|}{ Variable }} & Control Group $(n=49)$ & Alteplase Group $(n=53)$ & \multirow{2}{*}{ P-Value } \\
\hline & & $X \pm S D$ & $X \pm S D$ & \\
\hline \multicolumn{2}{|l|}{ Age (yr) } & $55.4 \pm 6.5$ & $54.7 \pm 7.1$ & 0.63 \\
\hline \multicolumn{2}{|c|}{ Pain to balloon time (min) } & $637.4 \pm 263.6$ & $588.9 \pm 281.7$ & 0.37 \\
\hline \multirow{2}{*}{ Gender } & Female & $14(28.6 \%)$ & $15(28.3 \%)$ & \multirow{2}{*}{0.97} \\
\hline & Male & $35(71.4 \%)$ & $38(71.7 \%)$ & \\
\hline \multicolumn{2}{|c|}{ Hypertension } & $19(38.8 \%)$ & $26(49.1 \%)$ & 0.30 \\
\hline \multicolumn{2}{|c|}{ Diabetes Mellitus } & $22(43.9 \%)$ & $29(54.7 \%)$ & 0.32 \\
\hline \multicolumn{2}{|c|}{ Dyslipidemia } & $16(32.7 \%)$ & $21(39.6 \%)$ & 0.46 \\
\hline \multicolumn{2}{|l|}{ Smoking } & $18(36.7 \%)$ & $12(22.9 \%)$ & 0.12 \\
\hline \multirow{4}{*}{ Killip class } & 0 & $14(28.6 \%)$ & $24(45.3 \%)$ & \multirow{4}{*}{0.11} \\
\hline & 1 & $18(36.7 \%)$ & $20(37.7 \%)$ & \\
\hline & 2 & $9(18.4 \%)$ & $3(5.7 \%)$ & \\
\hline & 3 & $8(16.3 \%)$ & $6(11.3 \%)$ & \\
\hline \multirow{4}{*}{ Baseline TTG } & 2 & $22(44.9 \%)$ & $21(39.6 \%)$ & \multirow{4}{*}{0.29} \\
\hline & 3 & $7(14.3 \%)$ & $12(22.6 \%)$ & \\
\hline & 4 & $14(28.6 \%)$ & $9(17.0 \%)$ & \\
\hline & 5 & $6(12.2 \%)$ & $11(20.8 \%)$ & \\
\hline \multicolumn{2}{|l|}{ Predilatation } & $43(87.8 \%)$ & $44(83.0 \%)$ & 0.50 \\
\hline \multicolumn{2}{|l|}{$N^{\circ}$ of stents } & $1.32 \pm 0.45$ & $1.15 \pm 0.38$ & 0.52 \\
\hline \multicolumn{2}{|c|}{ Maximum inflation pressure (atm) } & $14.7 \pm 1.8$ & $14.4 \pm 1.9$ & 0.45 \\
\hline
\end{tabular}

Table 2: Comparison between groups regarding clinical and angiographic outcome.

\begin{tabular}{|c|c|c|c|c|}
\hline \multirow{2}{*}{\multicolumn{2}{|c|}{ Variable }} & Control Group $(n=49)$ & \multirow{2}{*}{$\begin{array}{l}\text { Alteplase Group }(n=53) \\
X \pm \text { SD }\end{array}$} & \multirow{2}{*}{ P-Value } \\
\hline & & $X \pm S D$ & & \\
\hline \multicolumn{2}{|c|}{ Peak CK-MB (ug/L) } & $146.3 \pm 48.9$ & $132.1 \pm 54.4$ & 0.17 \\
\hline \multicolumn{2}{|c|}{ Peak Troponin I (ug/L) } & $8.6 \pm 3.2$ & $7.1 \pm 2.4$ & 0.008 \\
\hline \multicolumn{2}{|c|}{ ST resolution at $90 \mathrm{~min}$} & $34(69.4 \%)$ & $46(86.8 \%)$ & 0.033 \\
\hline \multirow{2}{*}{ Final TIMI flow } & 2 & $22(44.9 \%)$ & $27(55.1 \%)$ & \multirow{2}{*}{0.46} \\
\hline & 3 & $20(37.7 \%)$ & $33(62.3 \%)$ & \\
\hline \multicolumn{2}{|l|}{ cTFC } & $30.1 \pm 3.3$ & $19.3 \pm 3.0$ & $<0.001$ \\
\hline \multirow{3}{*}{ MBG } & 1 & $15(36.7 \%)$ & $11(20.8 \%)$ & \multirow{3}{*}{0.03} \\
\hline & 2 & $26(18.4 \%)$ & $21(39.6 \%)$ & \\
\hline & 3 & $8(16.3 \%)$ & $21(39.6 \%)$ & \\
\hline \multicolumn{2}{|c|}{ TIMI Major bleeding } & 0 & 0 & - \\
\hline \multicolumn{2}{|c|}{ TIMI Minor/minimal bleeding } & $4(8 \%)$ & $6(11.3 \%)$ & 0.24 \\
\hline \multicolumn{2}{|c|}{ In-hospital reinfarction } & $1(2 \%)$ & $1(1.9 \%)$ & 0.95 \\
\hline \multicolumn{2}{|c|}{ Reinfarction within 6 months } & $3(6.1 \%)$ & $4(7.5 \%)$ & 0.77 \\
\hline \multicolumn{2}{|c|}{ Post-PCI angina } & $3(6.1 \%)$ & $2(3.8 \%)$ & 0.58 \\
\hline \multicolumn{2}{|c|}{ Recurrent angina within 6 months } & $9(18.4 \%)$ & $10(18.9 \%)$ & 0.94 \\
\hline \multicolumn{2}{|c|}{ Stent thrombosis } & 0 & 0 & - \\
\hline \multicolumn{2}{|c|}{ Target vessel revascularization } & $3(6.1 \%)$ & $2(3.8 \%)$ & 0.58 \\
\hline \multicolumn{2}{|c|}{ Cardiac death } & $2(4.1 \%)$ & $1(1.9 \%)$ & 0.51 \\
\hline \multicolumn{2}{|c|}{ Non-cardiac death } & $1(2 \%)$ & $1(1.9 \%)$ & 0.95 \\
\hline
\end{tabular}

not adherent to medical treatment so they were excluded. Table 1 shows demographic and procedural data of the study population. It was a relatively young population with male preponderance. Diabetes mellitus and hypertension were the most commonly encoun- tered risk factors.

ST resolution $>50 \%$ was encountered in 44 and 31 patients of alteplase and control groups respectively ( $p$ value 0.033 ). Peak troponin I level was significantly 
lower in alteplase group. Despite final TIMI flow was comparable, CTFC was significantly lower and MBG was significantly higher in alteplase group reflecting better epicardial and myocardial flow. No TIMI major bleeding occurred in either group. TIMI minor/minimal bleeding rates were similar in both groups ( $p$ value 0.24). Regarding other clinical outcome endpoints, no significant difference was noted (Table 2).

Regarding echocardiographic data, mean GLS and longitudinal dyssynchrony were significantly improved in alteplase group both at 48 hours after PPCl and at 6 months follow-up. On the contrary, LV volumes and LVEF were comparable between both groups; with a trend toward higher improvement in LV geometry and LVEF in alteplase group (Table 3).

\section{Discussion}

The main findings in our study are that intracoronary alteplase after PPCI resulted in:

1. Significant improvement in epicardial and myocardial coronary flow without significant difference in TIMI major bleeding.

2. Significant improvement in LV longitudinal function (both acutely and at 6 months) with a trend toward improvement in LV volumes and LVEF (at 6 months).

To date, no large randomized trials evaluating the effect of intracoronary t-PA are available. Small studies on intracoronary thrombolysis performed in the 1980's and 1990's were confusing in terms of safety [27-29]. The largest experience reported was the Intracoronary
t-PA Registry, which enrolled 198 patients and found significant increase in TIMI flow as well as significant decrease in thrombus grade $(\mathrm{P}<0.0001$ for each). In this registry, bleeding rate was $9.2 \%$, post-PCI $\mathrm{MI}$ rate was $17.6 \%$, repeat $\mathrm{PCl}$ rate was $4.9 \%, 9.2 \%$ of patients needed $C A B G$, and in-hospital mortality rate was $7 \%$ [30]. More confusion had risen by studies on facilitated $\mathrm{PCl}$. However, with the high incidence of MVO and noreflow in the current $\mathrm{PCl}$ era, we tried to find a new solution with an old weapon.

This study was conducted on 102 patients presenting with STEMI who were randomly divided into two groups; control group (49 patients) who underwent PPCl only and alteplase group (53 patients) who underwent PPCI followed by intracoronary alteplase infusion. Both groups were matched for age and gender and there was no significant difference between both groups regarding coronary risk factors, Killip class at admission, pain to needle time, TIMI thrombus grade and final TIMI flow grade.

\section{Acute effects of intracoronary alteplase infusion}

In our study, significant improvements in epicardial (cTFC) and myocardial (MBG) coronaryflow were found with the use of low dose intracoronary alteplase. Using different intracoronary thrombolytics, Sezer, et al. [12] (using streptokinase) Boscarelli, et al., [13] (using alteplase and tenectplase) and Jayagopal and SarjunBasha, [14] (using tenectplase) found the same results. More physiologically, Sezer, et al. [12] found that coronary flow reserve, index of microvascular resistance and Pressure derived collateral flow index were significantly

Table 3: Comparison between echocardiographic data of both groups.

\begin{tabular}{|c|c|c|c|}
\hline Variables & Control Group (n = 49) & Alteplase Group ( $n=53$ ) & P-Value \\
\hline \multicolumn{4}{|l|}{ LVEDV (ml) } \\
\hline 48 hours after $\mathrm{PCl}$ & $140.4 \pm 16.4$ & $142.1 \pm 17.4$ & 0.45 \\
\hline 6 months after $\mathrm{PCl}$ & $127.3 \pm 29.1$ & $119.6 \pm 27.5$ & 0.16 \\
\hline \multicolumn{4}{|l|}{ LVESV (ml) } \\
\hline 48 hours after $\mathrm{PCl}$ & $77.4 \pm 14.6$ & $81.5 \pm 15.5$ & 0.17 \\
\hline 6 months after $\mathrm{PCl}$ & $62.1 \pm 25.9$ & $54.1 \pm 20.7$ & 0.08 \\
\hline \multicolumn{4}{|l|}{ LVEF (\%) } \\
\hline 48 hours after $\mathrm{PCl}$ & $43.6 \pm 3.0$ & $42.5 \pm 3.4$ & 0.08 \\
\hline 6 months after $\mathrm{PCl}$ & $52.29 \pm 8.7$ & $55.6 \pm 7.4$ & 0.09 \\
\hline Delta LVEF & $9.2 \pm 5.4$ & $13.0 \pm 5.8$ & 0.02 \\
\hline \multicolumn{4}{|l|}{ Mean GLS } \\
\hline 48 hours after $\mathrm{PCl}$ & $-15.5 \pm 1.1$ & $-16.1 \pm 1.1$ & 0.02 \\
\hline 6 months after $\mathrm{PCl}$ & $-17.1 \pm 3.3$ & $-20.6 \pm 0.75$ & $<0.001$ \\
\hline Delta mean GLS & $-2.9 \pm 1.6$ & $-4.5 \pm 1.3$ & $<0.001$ \\
\hline \multicolumn{4}{|c|}{ Mean peak S' velocity } \\
\hline 48 hours after $\mathrm{PCl}$ & $7.6 \pm 0.8$ & $7.4 \pm 0.9$ & 0.4 \\
\hline 6 months after $\mathrm{PCl}$ & $9.5 \pm 2.2$ & $10.1 \pm 1.20$ & 0.1 \\
\hline \multicolumn{4}{|c|}{ Maximum Q-S' time difference } \\
\hline 48 hours after $\mathrm{PCl}$ & $58.5 \pm 12.8$ & $52.6 \pm 9.6$ & 0.01 \\
\hline 6 months after $\mathrm{PCl}$ & $51.8 \pm 28.5$ & $24.6 \pm 8.2$ & $<0.001$ \\
\hline
\end{tabular}


lower in the group that received streptokinase $1<0.001$ each).

In the present study, GLS was found to be significantly higher in the group that received alteplase in spite of no difference in LV volumes or LVEF. We are the first to address the effect of post-PCl intracoronary thrombolysis on LV longitudinal function. Taking CMR as the reference, Biere, et al. [15] found that GLS correlated significantly with MVO and final infarct size. Moreover, in the speckle tracking substudy of the EXPIRA trial, Cimino, et al. [31] found that GLS was closely related to the degree of MVO.

In the present study, the percent of patients with > $50 \%$ ST resolution at 60 minutes were significantly higher in the alteplase group ( $p$ value 0.04). Using streptokinase, Sezer, et al. [12] did not find significant difference. Despite the strong correlation between ST resolution and microvascular integrity, some confounding factors are still to be considered e.g. effect of dyskinetic segments and dynamic nature of ST segment elevation.

In the present study, peak levels of troponin I were significantly less in the group that received alteplase reflecting, possibly, better microvascular perfusion and higher myocardial salvage. Peak troponin level after $\mathrm{PPCl}$ has been found to correlate infarct size [32] as well as microvascular perfusion [33].

The use of intracoronary alteplase did not increase the risk of TIMI major bleeding in our study. This may be due to many factors: First, the relatively young age of the study group with male preponderance. Secondly, using radial access in all cases mitigated the risk of access site bleeding. Finally, the administration of intracoronary alteplase through the suction catheter may have permitted local effect only.

\section{Late effects of intracoronary alteplase infusion}

In our study, we found that adjunctive intracoronary alteplase was associated with significantly higher GLS as well as a trend towards improvement in LV volumes and LVEF. This can be considered delayed effect of improved microvascular perfusion secondary to intracoronary thrombolysis.

Post-primary $\mathrm{PCl}$, the final infarct size and LV volumes and function are determined primarily by microvascular perfusion rather than epicardial TIMI flow. As a result, $20-32 \%$ of STEMI patients were found to exhibit LV remodeling in spite of TIMI 3 flow in IRA [4,34].

Diao, et al. [16] performed a meta-analysis on 765 patients included in 11 trials to find the correlation between GLS and late gadolinium enhancementmeasured infarct size. The pooled correlation was found to be $0.70(95 \% \mathrm{Cl}: 0.64,0.74)$ suggesting that GLS can be a surrogate parameter of infarct size. The correlation is rather superiorto conventional indices, including LVEF. In their 3-D echocardiography study, Iwahashi, et al. [35] recruited 190 patients with their first STEMI and found that GLS and longitudinal dyssynchrony are closely related to final infarct size and LV remodeling.

Thus, in our study, intracoronary alteplase could have limited the final infarct size and prevented subtle deterioration in LV function.

\section{Conclusions}

Low-dose intracoronary alteplase infusion immediately after successful primary $\mathrm{PCl}$ was compared to standard primary $\mathrm{PCl}$. We found acute improvement in microvascular perfusion as well as better LV GLS and longitudinal dyssynchrony without increasing bleeding risk.

\section{Limitations}

The small sample size precludes definite conclusions, yet, to date, this is the largest randomized study evaluating the role of intracoronary alteplase. The relatively few bleeding events may reflect selection bias. Cases with no-reflow were excluded because of its complex mechanism. Larger studies enrolling patients with cardiogenic shock and intra-aortic balloon bump are recommended.

\section{References}

1. Keeley EC, Boura JA, Grines CL (2003) Primary angioplasty versus intravenous thrombolytic therapy for acute myocardial infarction: A quantitative review of 23 randomised trials. Lancet 361: 13-20.

2. Kitabata H, Imanishi T, Kubo T, Takarada S, Kashiwagi $\mathrm{M}$, et al. (2009) Coronary microvascular resistance index immediately after primary percutaneous coronary interventionas a predictor of the transmural extent of infarction in patientswith ST-segment elevation anterior acute myocardial infarction. JACC Cardiovasc Imaging 2: 263-272.

3. Garot P, Pascal O, Simon M, JL Monin, E Teiger, et al. (2003) Impact of microvascular integrity and local viability on left ventricular remodelling after reperfused acutemyocardial infarction. Heart 89: 393-397.

4. Bolognese L, Carrabba N, Parodi G, Santoro GM, Buonamici $P$, et al. (2004) Impact of microvascular dysfunction on left ventricular remodeling and long-term clinicaloutcome after primary coronary angioplasty for acute myocardialinfarction. Circulation 109: 1121-1126.

5. Araszkiewicz A, Grajek S, Lesiak M, Prech M, Pyda M, et al. (2006) Effect of impaired myocardial reperfusion on left ventricular remodeling in patients with anterior wall acute myocardial infarction treated with primary coronaryintervention. Am J Cardiol 98: 725-728.

6. Bolognese L, Neskovic AN, Parodi G, Giampaolo Cerisano, Piergiovanni Buonamici, et al. (2002) Left ventricular remodeling after primary coronary angioplasty: Patterns of left ventricular dilationand long-term prognostic implications. Circulation 106: 2351-2357.

7. Galiuto L, Gabrielli FA, Lombardo A, Giuseppe La Torre, Antonio Scarà, et al. (2007) Reversible microvascular dysfunction coupled with persistent myocardial dysfunction: Implications for post-infarct left ventricular remodelling. Heart 93: 565-571. 
8. Kaul S, Ito H (2004) Microvasculature in acute myocardial ischemia. Part II. Evolvingconcepts in pathophysiology, diagnosis, and treatment. Circulation 109: 310-315.

9. Sakuma T, Sari I, Goodman CN, Lindner JR, Klibanov AL, et al. (2005) Simultaneous integrin alpha/beta3 and glycoprotein $\mathrm{Ilb} / \mathrm{Illa}$ inhibition causes reduction in infarct size in a model of acute coronary thrombosis and primary angioplasty. Cardiovasc Res 66: 552-561.

10. Henriques JP, Zijlstra F, Ottervanger JP, de Boer MJ, van't Hof AW, et al. (2002) Incidence and clinical significance of distal embolization during primary angioplasty for acute myocardial infarction. Eur Heart J 23: 1112-1117.

11. Sakuma T, Leong-Poi H, Fisher NG, Goodman NC, Kaul $S$ (2003) Further insights into the "no-reflow" phenomenon after primary angioplasty in acute myocardial infarction: The role of microthromboemboli. J Am Soc Echocardiogr 16: $15-21$.

12. Sezer M, Oflaz H, Goren $T$, İrem Okçular, Berrin Umman, et al. (2007) Intracoronary streptokinase after primary percutaneous coronary intervention. $\mathrm{N}$ Engl J Med 356: 1823-1834.

13. Boscarelli D, Vaquerizo B, Guardiola FM, Arzamendi D, Tizon $\mathrm{H}$, et al. (2014) Intracoronary thrombolysis inpatients with ST-segment elevation myocardial infarction presenting withmassive intraluminal thrombus and failed aspiration. Eur Heart J Acute Cardiovasc Care 3: 229-236.

14. Jayagopal PB, Khadhar Mohamed SarjunBasha (2018) Intracoronary tenecteplase in STEMI with massive thrombus. Indian Heart Journal 70: 446-449

15. Biere L, Donal E, Terrien G, Kervio G, Willoteaux S, et al. (2014) Longitudinal strain is a marker of microvascular obstruction and infarct size in patients with acute st-segment elevation myocardial infarction. PLoS One 9: E86959.

16. Diao KY, Yang ZG, Ma M, Yong He, Qin Zhao, et al. (2017) The diagnostic value of global longitudinal strain (GLS) on myocardial infarction size by echocardiography: $A$ systematic review and meta-analysis. Scientific Reports 7: 7-10082.

17. Killip T, Kimball JT (1967) Treatment of myocardial infarction in a coronary care unit. A two year experience with 250 patients. Am J Cardiol 20: 457-464.

18. De Lemos J, Braunwald E (2001) ST segment resolution as a tool for assessing the efficacy of reperfusion therapy. $J$ Am Coll Cardiol 38: 1283-1294.

19. Thygesen K, Alpert JS, Jaffe AS, Simoons ML, Chaitman $\mathrm{BR}$, et al. (2012) Third universal definition of myocardial infarction. Eur Heart J 33: 2551-2567.

20. The TIMI Study Group (1985) Thrombolysis in myocardial infarction (TIMI) trial. N Engl J Med 312: 932-936.

21. Gibson CM, Murphy SA, Rizzo MJ, Ryan KA, Marble SJ, et al. (1999) The relationship between the TIMIframe count and clinical outcomes afterthrombolytic administration. Circulation 99: 1945-1950.

22. Van't Hof AWJ, Liem A, Suryapranata H, Hoorntje JC, de Boer MJ, et al. (1998) Angiographic assessment of myocardial reperfusion in patients treated with primary angioplasty for acute myocardial infarction: Myocardial blush grade. Zwolle Myocardial Infarction Study Group. Circulation 97: 2302-2306.

23. Chesebro JH, Knatterud G, Roberts R, Borer J, Cohen LS, et al. (1987) Thrombolysis in myocardial infarction (TIMI) trial, phase I: A comparison between intravenous tissue plasminogen activator and intravenous streptokinase.Clinical findings through hospital discharge. Circulation 76: 142-154.
24. Srivastava PM, Burrell LM, Calafiore P (2005) Lateral vs medial mitral annular tissue Doppler in the echocardiographic assessment of diastolic function and filling pressures: Which should we use? Eur J Echocardiogr 6: 97-106.

25. Vieira MLC, Cury AF, Tavares GLP, Edgar Bezerra Lira Filho, Adriana Cordovil, et al. (2007) Left ventricular synchrony assessment: A comparativeanalysis using real time three-dimensional echocardiography and tissue Doppler imaging. einstein 5: 24-30.

26. Voigt JU, Pedrizzetti J, Lysyansky P, Marwick TH, Houle $\mathrm{H}$, et al. (2015) Definitions of a common standard of 2-D speckle tracking echocardiography: Consensus document of the EACVI/ASE/Industry Task Force to standardize deformation imaging. European Heart Journal-cardiovascular Imaging 16: 1-11.

27. Ambrose JA, Torre SR, Sharma SK, Israel DH, Monsen CE, et al. (1992) Adjunctive thrombolytic therapy for angioplastyin ischemic rest angina: Results of a double-blind randomized pilot study. J Am Coll Cardiol 20: 1197-1204.

28. Schieman G, Cohen BM, Kozina J, Erickson JS, Podolin RA, et al. (1990) Intracoronary urokinase for intracoronary thrombus accumulation complicating percutaneous transluminal coronary angioplasty in acute ischemic syndromes. Circulation 82: 2052-2060.

29. Morishita H, Hattori R, Aoyama T, Kawai C, Yui Y (1992) The intracoronary administration of urokinase following direct PTCA for acute myocardial infarction reduces early restenosis. Am Heart J 123: 1153-1156.

30. Intracoronary t-PA registry investigators. (1995) Clinical experience with intracoronary tissue plasminogen activator: Results of a multicenter registry. Cathet Cardiovasc Diagn 34: 196-201.

31. Cimino S, Agati L, Lucisano L, Mancone M, Petronilli V, et al. (2014) Value of two-dimensional longitudinal strains analysis to assess the impact of thrombus aspiration during primary percutaneous coronary intervention on left ventricular function: A speckle tracking imaging sub study of the EXPIRA trial. Echocardiography 31: 842-847.

32. Chia S, Senatore F, Raffel C, Lee H, Wackers FJ, et al. (2008) Utility of cardiac biomarkers in predicting infarct size, left ventricular function, and clinical outcome after primary percutaneous coronary intervention for st-segment elevation myocardial infarction. JACC Cardiovasc Interv 1: 415-423.

33. Younger JF, Plein S, Barth J, Ridgway JP, Ball SG, et al. (2007) Troponin-I concentration 72 hours after myocardial infarction correlates with infarct size and presence of microvascular obstruction. Heart 93: 1547-1551

34. Araszkiewicz A, Grajek S, Lesiak M, Prech M, Pyda M, et al. (2006) Effect of impaired myocardial reperfusion on left ventricular remodeling in patients with anterior wall acute myocardial infarction treated with primary coronary intervention. Am J Cardiol 98: 725-728.

35. Iwahashi N, Gohbara M, Kataoka S, Eiichi Akiyama, Nobuhiko Maejima, et al. (2015) The combination of dyssynchrony and global longitudinal strain by 3D speckle tracking after ST-elevation myocardial infarction is useful for prediction of final infarct size and left ventricular remodeling. JACC 65: 60192-60199. 